\title{
A Situation Semantics for Binding out of DP
}

\author{
Daniel Büring \\ UCLA
}

\begin{abstract}
In this paper I follow a suggestion in Bach and Partee (1980) to analyze the bound pronoun him in sentences like every boy's mother likes him and some person from every city likes it as paycheck pronouns (here: her son and his city, respectively). I demonstrate how such an approach affords an elegant treatment of weak cross-over. I then show that a direct implementation of this idea yields incorrect truth conditions. A refined implementation using quantification over minimal situations along the lines of Heim (1990) is proposed, which can handle the problematic cases and captures the cross-over facts.
\end{abstract}

\section{A Reinhartian Account of Pronoun Binding and Cross-Over}

Tanya Reinhart, in Reinhart (1983) and other works, has presented what I take to be one of the most elegant characterizations of the Weak Cross-Over (WCO) generalization:

Reinhart's Generalization:

Pronoun binding can only take place from a c-commanding A-position.

The crucial qualification here is 'from an A-position', which excludes binding from a position derived by $w h$-movement or quantifier raising. In the following, I will refer to this generalization as the a-command requirement on pronoun binding (where a-command $=\mathrm{c}$-command from an A-position).

For the purpose of the discussion, I will implement this generalization in the following way: We introduce a binding operator $\beta_{n}$, which can be optionally adjoined at LF. This operator signals that the DP immediately c-commanding it binds any free occurrence of a pronoun indexed $n$ within its c-command domain:

a. pronoun binding (optional): $\overbrace{\mathrm{DP} \mathrm{XP}}^{\Rightarrow_{L F}} \overbrace{\beta_{n} \overbrace{\mathrm{XP}}^{\mathrm{XP}}}^{\mathrm{PP}}$ where $n$ is an index, and DP occupies an A-position

b. $\llbracket \beta_{n} \mathrm{XP} \rrbracket^{w, g}=\lambda x \cdot\left[\llbracket \mathrm{XP} \rrbracket^{w, g\left[p r o n_{n} \rightarrow x\right]}(x)\right]^{1}$

Given the (fairly standard) interpretation of the binding operator (essentially Sag (1976)'s derived VP rule) and the explicit stipulation that it can only be adjoined next to an A-position we derive Reinhart's a-command requirement (1).

Almost, that is, for we need to ensure that no other mechanism can bind a pronoun from an $\bar{A}$ position, the most obvious candidate for that other mechanism being the rule that interprets operatortrace dependencies. For the sake of concreteness I will do this by formally distinguishing a trace binding operator $\mu_{n}$ (mnemonic for 'movement'):

a. trace binding (obligatory): ${ }_{\mathrm{DP}_{n} \mathrm{XP}}^{\Rightarrow} \overbrace{L F} \overbrace{\mu_{n} \mathrm{XP}}^{\mathrm{XP}}$ where $n$ is a movement index

b. $\llbracket \mu_{n} \mathrm{XP} \rrbracket^{w, g}=\lambda x \cdot \llbracket \mathrm{XP} \rrbracket^{w, g\left[t_{n} \rightarrow x\right]}$

R. Hastings, B. Jackson and Z. Zvolenszky (eds), SALT XI 56-75, Ithaca, NY: Cornell University. 
Note that crucially, the assignment function $g$ has a sorted domain: pronouns versus traces; that way it is possible that $g\left(t_{n}\right) \neq g\left(\right.$ pron $\left._{n}\right)$ for a given integer $n$. The standard WCO contrast between, say, (4a) and (b) is thus captured via the full LFs given below:

a. $\mathrm{Who}_{2}$ does his ${ }_{2}$ mother like $t_{2}$ ? b. $\mathrm{Who}_{2} t_{2}$ likes his ${ }_{2}$ mother?

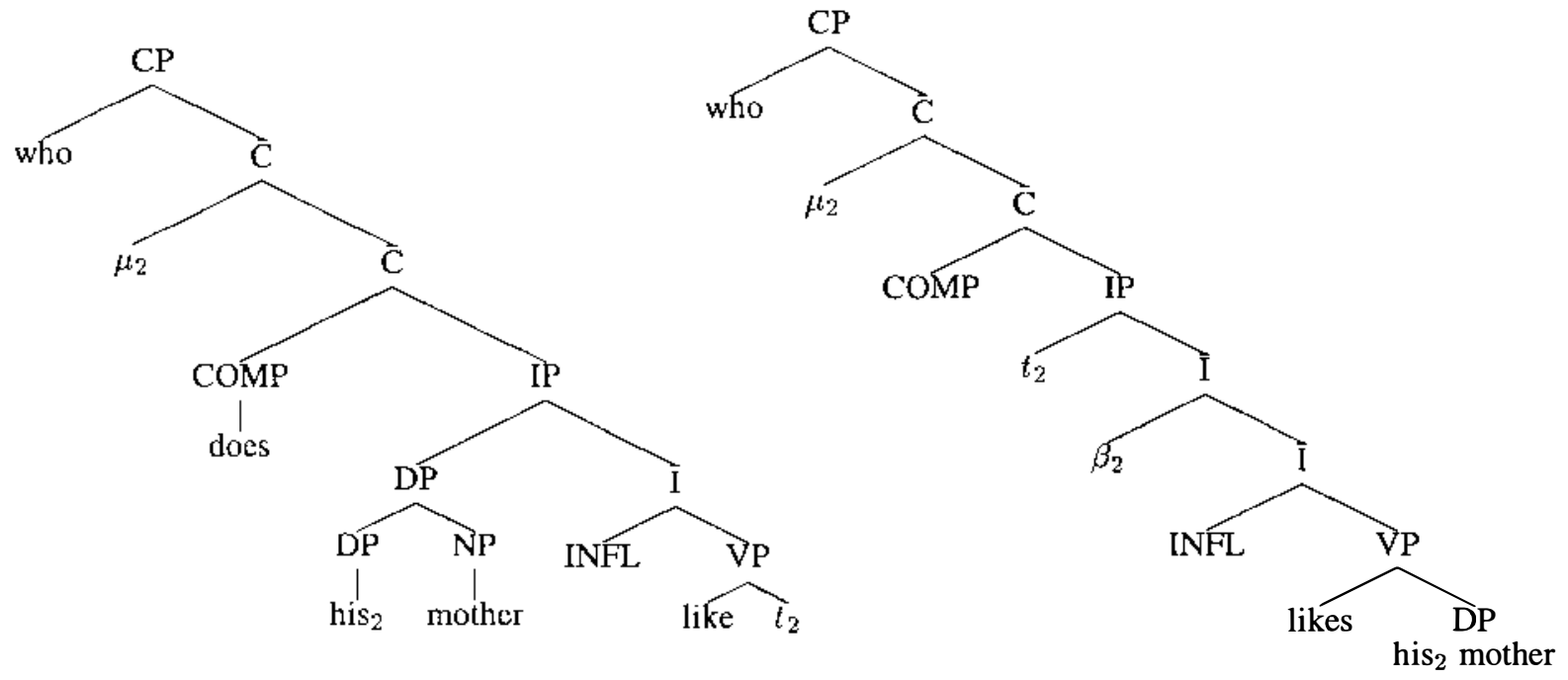

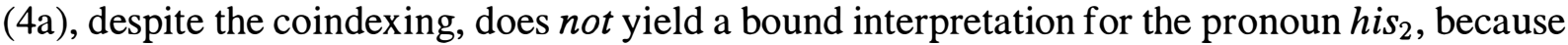
$\mu_{2}$ binds traces only; $h i s_{2}$ is interpreted as a free variable. For $h i s_{2}$ in (4a) to be bound, a $\beta_{2}$ operator would have to be inserted; but adjunction of $\beta_{2}$ to $\overline{\mathrm{C}}$ is not permitted, since SpecC is an $\overline{\mathrm{A}}$-position.

In contrast to that, (4b) has his 2 semantically dependent on who, because the trace of who binds it via the adjoined $\beta_{2}$. This adjunction is licit, since the trace occupies an A-position (if you believe that who in (4b) hasn't moved at all, the analysis gets even simpler; I just wanted to illustrate how a moved item can bind via its trace position in general).

To put the gist of this treatment a a slogan: $\overline{\mathrm{A}}$-dependencies and pronoun-binding dependencies are strictly distinct. This is diametrically opposed to treatments like in Heim and Kratzer (1998):ch.5, in which pronoun binding is taken as a side effect of $\bar{A}$-trace binding. It is similar in spirit to treatments such as Jacobson (1999), where pronoun binding is a semantic operation on predicates.

Maybe there is a more principled reason why binding from an $\bar{A}$-position cannot bind pronouns, namely that the traces of $\overline{\mathrm{A}}$-movement are of a semantic type other than $\langle\mathrm{e}\rangle$, so that no binding of an individual variable can occur as a 'side effect' of $\bar{A}$-trace binding (as has been suggested recently in Ruys (2000)). This would avoid the stipulated restriction on $\beta$-adjunction to A-positions. I will not speculate on this further, but everything that follows is compatible with such a refinement.

It bears mentioning that the implementation of WCO made here is extremely local. In particular, no reference to the potential bindee and its configuration relative to the binder is made; in fact no reference to chains or indices is made at all, which resonates well with the idea endorsed in Categorial Grammar and more recently certain versions of the Principles \& Parameters Theory that the internal structure of constituents, once they have been constructed, is opaque to further grammatical operations.

\section{Embedded Quantifier Binding}

Both parts of Reinhart's generalization are challenged by data like the following, much discussed in the literature cited here and elsewhere, which I will refer to as embedded quantifier binding (EQB) (here and henceforth, italics mark referential dependencies): 
Binding from SpecD

a. Whose mother loves him/his sister? (May (1988):90)

b. Some boy's father's best friend's daughter wants him to marry her. (Higginbotham (1980):691)

Inverse Linking (May (1977), May (1985)) ${ }^{2}$

a. Somebody from every city despises it/its architecture. (May (1988):89)

b. Every daughter of every professor in some small college town wishes she could leave it. (Higginbotham (1980):690)

In all of these examples, the binding DP doesn't c-command the bound pronoun at all (see Hornstein (1995) for a different point of view). If one assumes that c-command is established via quantifier raising at LF, that derived position will be an $\overline{\mathrm{A}}$-position; so either way, it seems impossible to maintain (1).

These examples are instances of a larger phenomenon of binding out of $D P$, which includes donkey sentences, sloppy identity in verb phrase ellipsis, co-variation with focused DPs, dependent plurals, and possibly more (see Heim (1990), Tomioka (1999), Dimitriadis (1999) and the references therein). The analysis to be proposed here for EQB uses the same mechanism employed by the authors just mentioned, thereby unifying all these cases. Although I don't have the space to show this here, I think that such a uniform treatment is warranted, given the parallel behavior of all of them with regard to Cross-Over, ellipsis and other facts. It is also worth noting that the problems addressed in the second half of this paper haunt all these analyses alike. The machinery proposed might thus have merits beyond the set of data discussed in this paper.

\section{Relevant Generalizations and a First Semantic Account}

\subsection{Generalizations}

Before turning to the analysis of the cases presented in the previous section, I want to outline a few essential properties that I think delimit the set of viable analyses for them (I cannot provide a comparison with other theories here, cf. Büring (2001) for that, but the reader might be able to verify that the analysis to be developed sits particularly well with the facts mentioned in this section). For the rest of the paper I will use the following terminology: I'll refer to the embedded DP with which the bound pronoun co-varies as the antecedent $D P$, or ADP for short, while the DP containing the ADP and a-commanding the pronoun is referred to as the container DP (CDP). The pronoun is sometimes simply called the bindee.

Binding Theory: We observe that the ADP does not trigger Binding Principle A-C effects in the bindee site:
a. *Everyone's escort suited himself. (Hornstein (1995):120)
b. No one's mother kissed him. (ibd:107)
c. The Smith's maid speaks well of the Smiths. (Lasnik (1976):100)

What this indicates is that the ADP does not behave like it a-commands the bindee. We should hence not try to assimilate EQB cases to bona fide A-binding.

Scope: It has been pointed out that the ADP and the CDP cannot be scopally dissociated (Barker (2001a,b), Heim and Kratzer (1998):232ff., Huang (1982), Larson (1987)): 
a. What does somebody from every city despise? (no scope of every city over what; May (1985):70)

b. Two politicians spy on someone from every city.

i. every - some - two

ii. two - every - some

iii. *every - two - some

I conclude from that the pronoun binding should not be derived by extracting the ADP from the CDP and adjoining it to a clausal node.

Cross-Over: Strikingly, the ADP can bind exactly those DPs which the CDP a-commands, the socalled Secondary Weak Cross-Over effect:

a. Everybody in some city hates its climate.

b. $*$ Its climate is hated by everybody in some city. (Higginbotham (1980):693:(82/3))

The moral: It seems impossible to derive the cross-over facts from a condition on the position of (the trace of) the ADP alone.

\subsection{A First Stab at the Semantics}

To get Binding Theory facts and the scope facts right I follow May (1985) in assuming that the ADP adjoins to the CDP at LF:

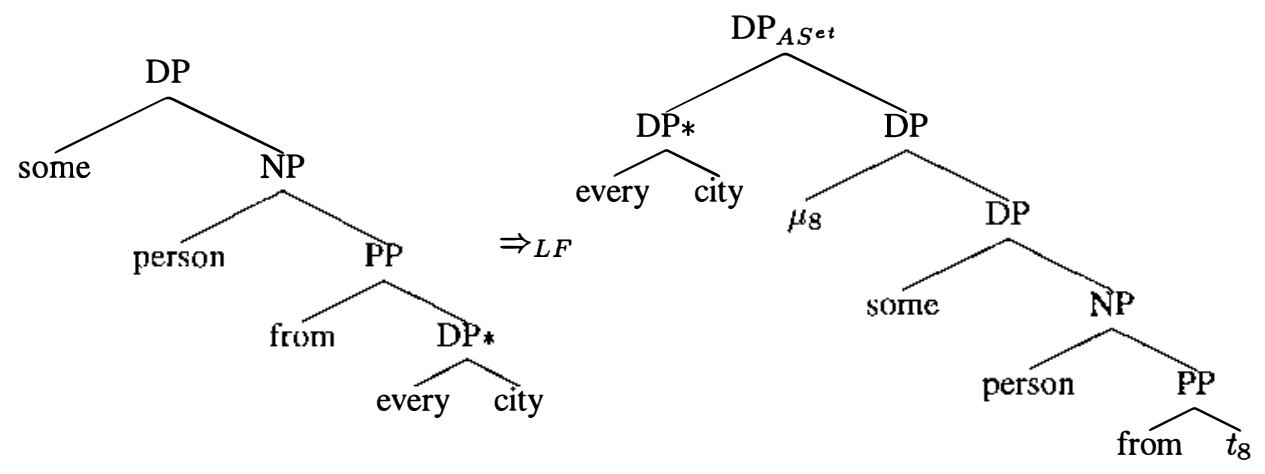

I've marked the highest DP node with a subscript $A S^{e t}$. This is because the meaning of this node cannot be derived by function application: The lowest DP at LF, some person from $t_{8}$ is a generalized quantifier of type $\langle\mathrm{et}, \mathrm{t}\rangle$. Hence $\mu_{8}$ some person from $t_{8}$ is of type $\langle\mathrm{e},\langle\mathrm{et}, \mathrm{t}\rangle\rangle$. For that to combine with every city we need a simple composition rule argument saturation, which allows a generalized quantifier to combine with any category of type $\langle\mathrm{e},\langle\ldots \mathrm{t}\rangle\rangle$ and 'pass on' any argument position corresponding to the dots: ${ }^{3}$

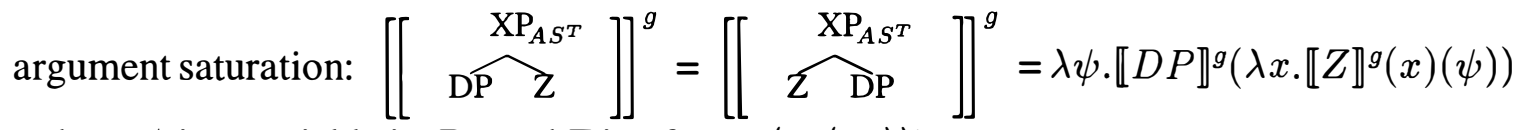
(where $\psi$ is a variable in $D_{T}$ and $Z$ is of type $\langle\mathrm{e},\langle\mathrm{T}, \mathrm{t}\rangle\rangle$ )

Given that, the composition can proceed smoothly: 
a. 【some person from $t_{8} \rrbracket^{w, g}=\lambda P \cdot\left[P \cap\left\{x \mid x\right.\right.$ is a person in $w$ and from $g\left(t_{8}\right)$ in $\left.\left.w\right\} \neq \varnothing\right]$

b. $\llbracket \mu_{8}\left[\right.$ some person from $\left.t_{8}\right] \rrbracket^{w, g}=\lambda x_{1} \cdot \lambda P .\left[P \cap\left\{x_{2} \mid x_{2}\right.\right.$ is a person in $w$ and from $x_{1}$ in $w\} \neq \varnothing]$

c. $\llbracket$ every city $\rrbracket^{w, g}=\lambda P \cdot[\{x \mid x$ is a city in $w\} \subseteq P]$

d. $\llbracket$ every city $\mu_{8}\left[\right.$ some person from $\left.t_{8}\right] \rrbracket^{w, g}=$ $\lambda P_{1} \cdot\left[\lambda P_{2} \cdot\{x \mid x\right.$ is a city in $\left.w\} \subseteq P_{2}\right]\left(\lambda x_{3} \cdot\left[\lambda x_{1} \lambda P_{3} \cdot P_{3} \cap\left\{x_{2} \mid x_{2}\right.\right.\right.$ is a person in $w$ and from $x_{1}$ in $\left.\left.\left.\left.w\right\} \neq \varnothing\right\}\right]\left(x_{3}\right)\left(P_{1}\right)\right)$

$=\lambda P_{1} \cdot\{x \mid x$ is a city in $w\} \subseteq\left\{x_{3} \mid P_{1} \cap\left\{x_{2} \mid x_{2}\right.\right.$ is a person in $w$ and from $x_{3}$ in $w\} \neq \varnothing\}\}$

This quantifier meaning can combine with a VP like attended the meeting to give us the correct meaning, roughly 'for every city there was someone from that city who attended the meeting'.

It does not, however, yield a bound pronoun interpretation for a sentence like somebody from every city likes its beaches, given that every city doesn't a-command its. One can think of a number of more or less ad hoc amendments to the semantics to solve this problem. The natural assumption would be that the CDP exceptionally denotes a binary quantifier over individuals (e.g. $\lambda R$.for every city $x_{1}$, there is a person $x_{2}$ from $x_{1}$ such that $R\left(x_{1}\right)\left(x_{2}\right)$ ), and its argument, the VP, denotes a relation (e.g. $\lambda x_{1} \cdot \lambda x_{2} \cdot x_{2}$ likes $x_{1}$ 's beaches). The task is then to compositionally derive those non-standard meanings, and implement the Cross-Over generalization on them.

In what follows I will take a different route, one which assumes that everything has its ordinary meaning. As a first go this means that the CDP denotes a unary quantifier and its argument denotes a property. In the second half of the paper I will then refine this view.

\section{Using Paycheck Pronouns}

\subsection{The Analysis}

Bach and Partee (1980), recognizing cases of EQB such as (5) as problematic for their counterpart to the c-command requirement for binding, propose in passing to re-analyze them using paycheck pronouns. This suggestion has to the best of my knowledge never been taken up in the literature. Let us implement it by analyzing the configuration (13a) via the LF in (13b), which gets an interpretation equivalent to (13c) through contextual assignment of the 'son of' function to the variable $R$ (this adopts the treatment of paycheck pronouns in Cooper (1979) and Heim and Kratzer (1998)):

a. [Every boy's mother] loves him?

b. every boy's mother $\left[\beta_{2}\left[\right.\right.$ loves [ THE $\left.\left.\left.R\left(x_{2}\right)\right]\right]\right]$

c. Every boy's mother loves her son?

Individual variables like $x_{2}$ are assigned the syntactic category of pronouns, which means they can get bound by $\beta$, but not $\mu$. The complete LF for e.g. an inverse linking case will then look as in (14):

$$
\text { Some person from every city likes it. }
$$




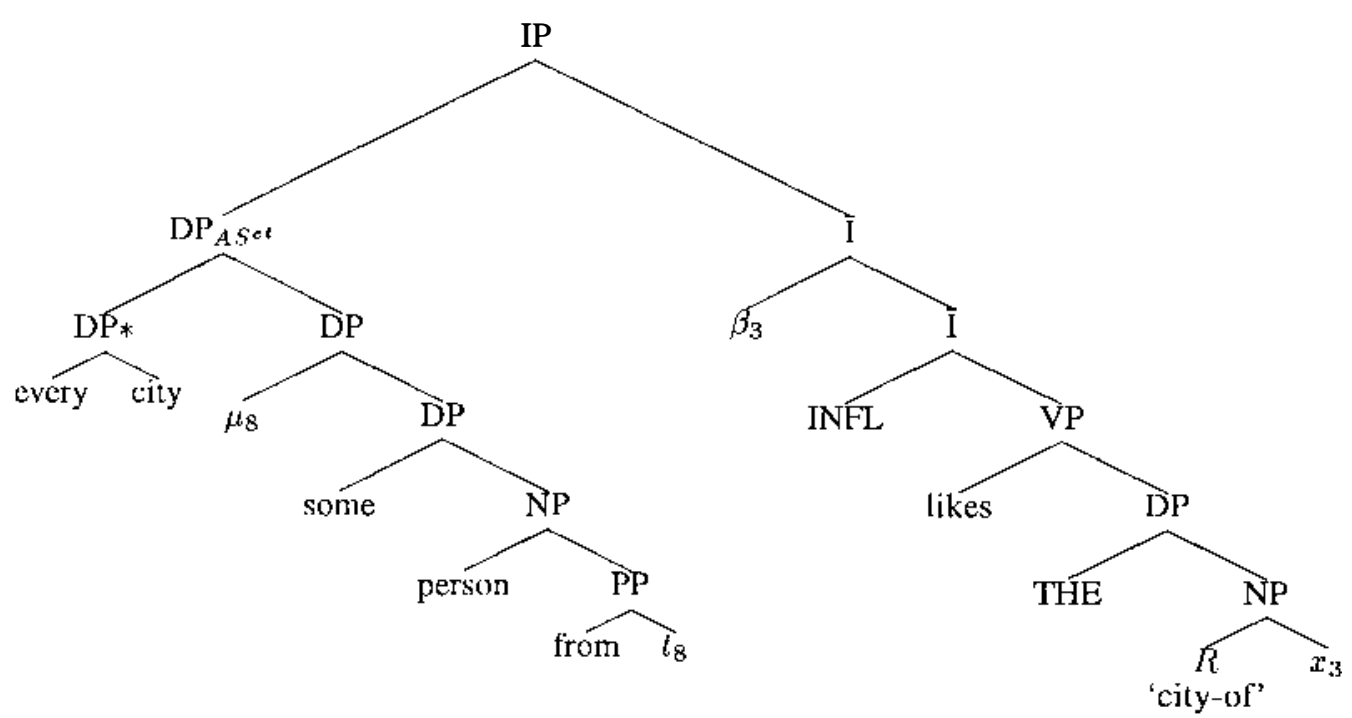

As informally indicated, the variable $R$ will be contextually instantiated as a function that maps individuals to the set of cities they are from, so that the whole sentence gets the contextual interpretation 'for every city $x_{8}$, there is some person $x_{3}$ from $x_{8}$ such that $x_{3}$ likes the city $x_{3}$ is from'.

Crucially, the only object language variable that is bound here is $x_{3}$, and it is bound by the CDP somebody from every city, not the ADP every city (note the change in italicization in (13)). Since the CDP a-commands the variable this binding conforms to Reinhart's generalization.

This means that the CDP can have its standard interpretation as a unary quantifier over individuals (here: people); no non-standard meanings need to be derived. Furthermore, the Cross-Over facts follow directly: It is the CDP that does the actual binding, and so the CDP must a-command the bindee, which was our original generalization. We thus capture the secondary WCO cases discussed in section 3.1, such as the impossibility of a bound pronoun interpretation of $*$ Whose mother does his sister like?, which is now entirely parallel to ordinary WCO cases such as $*$ Who does his mother like? in (4).

\subsection{Problems and Open Questions}

Unfortunately, the analysis as is runs into a number of problems, some of which are serious enough to warrant substantial modifications.

Uniqueness: The first and foremost problem concerns uniqueness. Given that we have analyzed the bound pronoun as essentially a function from individuals to individuals, it follows that it will not be defined if no such functional mapping exists. A sentence like (15a) for example is predicted to be either false or undefined if there are mothers that have more than one son:

a. Every boy's mother likes him.

b. Some ally of every country betrayed it.

This result is counter-intuitive. We clearly judge (15a) to be true just in case every boy has a loving mother; likewise, (15b) requires that every country has at least one deceitful ally (this shows that a maximal sum interpretation for the paycheck pronoun won't work either). These are exactly the truth conditions we get under a binary quantification analysis, but they do not follow from any version of the unary quantification analysis given above.

VP-Ellipsis: As Philippe Schlenker (p.c.) pointed out to me, assuming that the pronoun is a hidden 
description with a variable in it predicts that that variable should be able to be re-bound in VP-ellipsis contexts. To see this, simply take the analysis literally and assume that him in e.g. (16a) is their son. Then the VP-ellipsis site should be resolved to Mary and Bill don't like their son, and it should be possible to get a sloppy interpretation for their, i.e. bind it to Mary and Bill, just as she in Every girl thinks she is great, and Mary does, too. This prediction does not seem to be borne out:

a. Every boy's parents like him, but Mary and Bill don't (not: '... like their son')

b. Somebody from every city likes its beaches, but Mary doesn't. (not: '... doesn't like her city's beaches')

A binary quantification analysis, on the other hand, does not run into this problem, given that only a complex DP, i.e. on with an embedded quantifier, is expected to show binding effect of this type.

Formal Link: Finally, since the analysis above crucially relies on a contextually provided relation variable, the obvious question arises what constraints the instantiation of that variable, a problem Heim (1990), following Kadmon (1987) calls the problem of the formal link; the problem is illustrated by the contrast between the donkey-less donkey sentences in (17):

a. Everyone who has a guitar should bring it. (it $\approx$ 'his (or her) guitar')

b. Every guitarists should bring it. ( $*$ with $i t \approx$ 'his (or her) guitar')

EQB constructions raise an analogous question, as (18) illustrates: Assuming, as the paycheck analysis does, that $i t$ is interpreted as [THE $R x$ ] with $x$ bound by the subject DP and $R$ contextually instantiated as the 'child-of' function, why is that function contextually available in (18a), but not in $(18 b)$ ?

a. Every child's mother loves it. (it $\approx$ 'her child')

b. Every mother loves it. (* with it $\approx$ 'her child')

Obviously, no analogous problem exists for the binary quantification analysis as outlined above, where the pronoun is simply interpreted as an individual variable.

\subsection{Conclusion}

The conclusion from subsection (4.2) is that a unary quantification analysis such as the one sketched in subsection (4.1) is semantically not tenable (because of the uniqueness problem), and syntactically problematic. At the same time, the scope data presented in section (3.1) argue for treating the entire CDP as a constituent at LF. Taken together, these two points entail that the CDP has to denote a binary quantifier.

On the other hand, quite a bit can be said in favor of the paycheck analysis in general: It provides an extremely simple and straightforward account of the Cross-Over data. Furthermore the semantic operations used for composing the meaning of the CDP and for pronoun binding are straightforward and compositional (by 'straightforward' I mean 'do not have to be formulated especially for the case at hand').

In addition, some more general points deserve consideration: Paycheck pronouns (or their close cousins, e-type pronouns, which I do not distinguish for the purpose of this paper) are required independently (cf. Evans (1977, 1980), Neale (1990), Heim and Kratzer (1998):ch.11 and references there). Furthermore they have been widely used in the analysis of a wealth of phenomena that quite arguably involve referential dependencies between DPs that do not stand in a c-command relation, among them the binding out of DP data mentioned in subsection 2, as well as Bach-Peters sentences (cf. Jacobson (1977), Jacobson (2000)). If EQB could be subsumed under this group, we would have a uniform and 
parsimonious treatment of all these cases, which none of the other approaches (to wit formation of binary individual quantifiers and unselective binding, which I can't discuss here) seems to be able to provide.

I will therefore explore an analysis which lets us have the cake and eat it, too, as it were: I will treat the CDP (in fact any DP) as a binary quantifier over individual+situation pairs, and analyze the pronouns as definite descriptions (i.e. paycheck pronouns) that are situation-dependent.

\section{Enter Situation Semantics}

Heim (1990), elaborating on Berman (1987) provides a situation semantics version of a paycheck account to donkey sentences which avoids the uniqueness problem. Simplifying considerably, she lets the equivalent to the container DP in donkey sentences, say every man who owns a donkey denote a binary quantifier which quantifies over pairs of an individual and a situation, here: minimal situations of a farmer and a donkey he owns. Every farmer who owns a donkey beats it is thus, to a first approximation, given the interpretation 'every minimal situation containing a farmer and a donkey owned by him is (or can be extended to) one in which he beats the unique donkey he owns in that situation'

Elbourne, in a series of recent papers (Elbourne (2000a,b, 2001)) elaborates on Heim's proposal, pointing out among other things that the description 'the unique donkey he owns in that situation' above can simply be replaced by 'the unique donkey in that situation', given that we are talking about minimal farmer+donkey-he-owns situations anyway. Put in different terms, Elbourne observes that the three variants in (19) are judged to have the same truth conditions (though they differ in their degree of naturalness):

$$
\text { Every farmer who owns a donkey beats }\left\{\begin{array}{l}
\text { it } \\
\text { the donkey } \\
\text { the donkey he owns }
\end{array}\right\}
$$

He suggests that if we assume the plain definite the donkey rather than the definite with a bound pronoun in it to be the LF representation for the paycheck pronoun, we can formulate a simple condition on the formal link, namely: identity of NP. That is, the reason we can have a paycheck pronoun reading in everyone who has a guitar should bring it but not in every guitarist should bring it is that we need to interpret it as 'the guitar', which is possible only if an NP guitar exists in the linguistic context.

In the analysis to be presented I will follow Elbourne's suggestion, though its predictions might ultimately be too restrictive. I will discuss some of my reasons in subsection 8.3. The analysis I want to explore, then will assign to a sentence like every boy's mother loves him an interpretation roughly as in (20):

for every boy, the minimal situation containing him and his mother is (or can be extended to) a situation in which she loves the unique boy in that situation

A treatment along these lines not only answers the formal link question, but will also - and more importantly - yield the desired truth conditions to at least the same extend that Heim (1990)'s treatment (and those building on it, among them Elbourne op.cit., von Fintel (1994), Tomioka (1999)) does. In particular, it will not run into a problem with uniqueness (I'll return to issues around VP ellipsis in section 8.1).

Will it enable us to capture the binding and cross-over facts in a fashion that still deserves to be called 'simple and straightforward'? To even begin to answer that question I will need to substantially elaborate on the existing treatments. 


\section{Taking Advantage of the Situation}

\subsection{Basics: I-Binding and S-Binding}

As outlined in the previous section, we aim to analyze our sentences entirely parallel to overt examples of dependent definites as in (21):

a. Every boy's mother likes the boy.

b. Some person from every city likes the city.

Such dependent definites do not only occur with embedded quantifiers as antecedents, but can also be directly c-commanded by their antecedent, provided that they do not thereby violate Principle $\mathrm{C}$ of the binding theory: ${ }^{4}$

a. Most modern cars let the driver adjust the mirrors from the inside.

b. Some movies are so long that you forgot the title by the time they end.

c. The green car has the hood painted blue (while the red car has the hood painted orange).

I will therefore distinguish between $i$-binding, by which I refer to the standard binding of an individual denoting pronoun as accomplished by the $\beta$ operator introduced in section 1 , and $s$-binding, i.e. binding of a situation variable (within a definite DP) as found in (22), for which I will introduce a binding operator $\Sigma$.

A DP like some movies will then quantify not just over individuals (that is: movies), but movie+situation pairs (namely minimal situations containing that movie). ${ }^{5}$ If the DP the title is sbound by some movies it will refer for each movie to the unique title in the minimal movie situation, which, lo and behold, is the movie's title.

To flesh this out formally we have to introduce situations into our ontology, together with a partial ordering $\leq$, meaning 'part of'. A subset of the set $S$ of situations is the set of worlds, i.e. those situations which are not proper parts of other situations. Each situation $s$ is part of exactly on world (namely $\iota s^{\prime} \in S\left[s \leq s^{\prime}\right.$ and $\forall s^{\prime \prime} \in S$, if $s^{\prime} \leq s^{\prime \prime}$, then $\left.s^{\prime}=s^{\prime \prime}\right]$ ). which we notate as $w_{s}$ ("the world of $\left.s^{\prime}\right)$, cf. Kratzer (1989)).

Our semantic types will remain standard, but the domain of type $\langle t\rangle$ is now the power set of $S$, i.e. sentences denote sets of situations (called propositions), VPs denote functions from individuals to sets of situations, and so forth. Accordingly, we no longer need a world index on the interpretation function, which is then plain $\llbracket \rrbracket^{g}$. I will usually write e.g. $\lambda x .\{s \mid \ldots\}$ to designate a function of type $\langle\mathrm{et}\rangle$, and analogous for other types ending in $\langle\mathrm{t}\rangle$, though nothing hinges on the mixture of set- and $\lambda$-notation.

\subsection{The Definite Article}

In the present analysis, both paycheck pronouns and DPs with prenominal genitives are analyzed as definite descriptions. Following the literature mentioned above, we could be tempted to assign the definite article the a meaning as in (23) (I ignore the question of which elements of the should be presuppositions here):

$\llbracket$ the $\rrbracket^{g}=\lambda P_{1} . \lambda P_{2} .\left\{s \in S \mid\right.$ there is an $x$ such that $x$ is the unique element in $P_{1}$ in $s$, and $\left.s \in P_{2}(x)\right\}$

A sentence like the cart is rolling will then denote the following proposition:

$\{s \in S \mid$ there is an $x$ which is the unique cart in $s$ and $x$ is rolling in $s\}$ 
This set will contain all situations which contain a rolling cart and possibly other things, but not a second cart. In a world $w$ which has two carts, one or both of which roll, (24) will contain a number of situations $s \leq w$, but not $w$ itself (or any situation $s^{\prime}, s \leq s^{\prime} \leq w$ which contains more than one cart). Such a proposition is called non-persistent (a persistent proposition is one that contains for every situation $s$ in it also all $s^{\prime}$ for which $s \leq s^{\prime}$ ).

Kratzer (1989) argues that persistence is a desirable property for propositions to have, and that quantifier meanings should be construed so as to yield persistent propositions. Therefore, I will assign special indices to determiners, which name the restricting situation for the determiner; the domain of assignment functions will be extended to contain a special set of variables, $\sigma_{1} \ldots \sigma_{n}$, which are mapped onto situations. Thus the $e_{\sigma_{1}}$ cart rolled will, for any assignment $g$, denote the set of situations $s$ in which the unique cart in $g\left(\sigma_{1}\right)$ was rolling.

Situation indices on determiners can (optionally) be s-bound by QDPs. We mark this binding by a special symbol at LF, $\Sigma_{n}$. A sentence like (22c) has thus the representations shown below:

a. the green car has the $\sigma_{\sigma_{1}}$ hood painted blue

b. the green car $\left[\Sigma_{1}\left[\right.\right.$ has the $\sigma_{\sigma_{1}}$ hood painted blue $\left.]\right]$

(25a) has the indexed $\sigma_{1}$, which is a free variable. The sentence will only be defined for $g$ which assign a situation containing a unique car to $\sigma_{1}$. If it is defined, it will denote a persistent proposition, since the car doesn't vary with the index situation. (25b) has $\sigma_{1}$ bound by the subject QDP. The result is a dependent reading where the hood depends on the car.

I left the subject determiner the in (25) unindexed. This was merely a simplification. For the purpose of achieving absolute uniqueness, we use a special subscript $\sigma_{0}$, which means that for any given $s$, the is interpreted relative to $w_{s}$ (i.e. the $\sigma_{\sigma_{0}} c a r$ is the unique car in the world). A complete representation for our sentence (25) then is The $\sigma_{0}$ green car $\left[\Sigma_{1}\left[\right.\right.$ has the $\sigma_{\sigma_{1}}$ hood painted blue]]. This sentence indeed denotes a persistent proposition.

\subsection{Cross-Over and S-Binding}

It turns out that s-binding is subject to Weak Cross-Over in the same way that i-binding is. The following sentences illustrate this:

a. Every movie exceeded the budget.

b. The producer financed every movie.

While the (26a) can be understood with the definite being s-bound by the subject DP (the budget = 'its budget'), no analogous reading is possible in (26b); it can only be understood to talk about one specific, contextually given producer.

I conclude that s-binding, too, can only take place from an A-position, and assume that $\Sigma$, the sbinding operator, can be adjoined next to a DP in an A-position only, just like $\beta$, the i-binding operator (see (32c) below for formalization).

\subsection{The Quantifier}

Let us finally turn to the semantics of the binder DP. Suppose we assume the following meaning for every:

$\llbracket$ every $\mathrm{A} \mathrm{B} \rrbracket^{g}=\left\{s \mid\right.$ for all $x$, if $w_{s} \in \llbracket \mathrm{A} \rrbracket^{g}(\mathrm{~s})$, then every $s^{\prime} \leq s$ in $\min \left(\llbracket \mathrm{A} \rrbracket^{g}(\mathrm{x})\right)$ is also in $\left.\llbracket \mathrm{B} \rrbracket^{g}(x)\right\}$

(where $\min (p)$ is the set of minimal situations in $p$, i.e. $\left\{s \in p \mid\right.$ for all $s^{\prime} \in p$ if $s^{\prime} \leq s$, then $\left.s^{\prime}=s\right\}$ ) 
According to this, a situation $s$ is in the proposition expressed by every man owns a balalaika if for every individual $x$, every sub-situation $s^{\prime} \leq s$ which is a minimal $x$-being-a-man situation is a situation in which $x$ has a balalaika. Since minimal being-a-man situations contain a man and nothing else, this proposition will contain men-less situations only, contrary to intuitions.

Suppose then we replace '. . is also in $\llbracket \mathrm{B} \rrbracket^{g}(\mathrm{x})$ ' in the above definition by '.... can be extended to a situation $s^{\prime \prime}, s^{\prime} \leq s^{\prime \prime}$ such that $s^{\prime \prime} \in \llbracket \mathrm{B} \rrbracket^{g}(\mathrm{x})^{\prime}$. Then the above sentence is true if every minimal $x$-being-a-man situation can be extended to a $x$-owning-a-balalaika situation; this yields the correct truth conditions for this example.

But what happens if we use a definite within the second argument of every? Take a sentence like (28a), assuming that the woman is s-bound by every man in Athens. We then get the truth conditions in $(28 \mathrm{~b})$ :

a. Every man in Athens greeted the woman.

b. $\quad\left\{s \mid\right.$ for all $x$, if $x$ is a man in Athens in $w_{s}$ then every $s^{\prime} \leq s$ which is a minimal situation of $x$ being a man in Athens can be extended to a situation $s^{\prime \prime}, s^{\prime} \leq s^{\prime \prime}$ in which he greeted the unique woman in $\left.s^{\prime \prime}\right\}$

Suppose every man in Athens greeted two or more women, but there is no woman greeted by every man. Then (28) is predicted to be true, since for each situation $s^{\prime}$ that contains just a man it is possible to find (at least) one situation $s^{\prime \prime}, s^{\prime} \leq s^{\prime \prime}$ containing that man and a woman he greets. Since that woman is unique in that situation, the truth conditions for the sentence are fulfilled.

This result of course clashes with our intuitions, according to which (28) can only be interpreted to mean that every man greeted one and the same woman, who is unique relative to some situation that doesn't covary with men (say the woman who is the current star at the theater). While we can represent this reading by not s-binding the article in the woman to every man in Athens, the question remains how to block the unwanted reading (the same problem haunts, as far as I can see, the analysis in Heim (1990), though technical details differ).

I propose therefore to go back to our original semantics for every in (27), which quantified over minimal situations. Obviously this precludes the woman from being s-bound by every man in Athens (since the situation the latter quantifies over are too minimal), but it also gets us straight back to square one when it comes to get a reasonable interpretation at all.

To remedy this we adopt from Heim (1990): 156, elaborating on Kadmon (1987), an operator that allows for extensions of situations:

$$
\llbracket \leq A \rrbracket^{g}=\left\{s \mid \text { there is a situation } s^{\prime}, s \leq s^{\prime} \text { such that } s^{\prime} \in \llbracket \mathrm{A} \rrbracket^{g}\right\}
$$

The representation of our pertinent example is now (30) (application of $\leq$ to a property-denoting expression should be straightforward, see the next section for details):

$$
\text { Every man in Athens }\left[\leq\left[\text { knows the } \sigma_{9} \text { woman }\right]\right]
$$

This sentence will be true if every minimal man-in-Athens-situation can be extended to a hegreets-the-unique-woman-in- $g\left(\sigma_{9}\right)$ situation, where $g\left(\sigma_{9}\right)$ must be a contextually given single-woman situation. This is intuitively correct. S-binding the woman to every man in Athens (i.e. every man in Athens $\left[\Sigma_{9}\left[\leq\left[\right.\right.\right.$ greets the $\sigma_{9}$ woman $\left.\left.]\right]\right)$ will again yield no interpretation (because $g\left(\sigma_{9}\right)$ would be a minimal man-in-Athens situation).

But can we s-bind the woman to the extended situation, which would yield the wrong truth conditions we had in (28b)? No! The prerequisite LF - Every man in Athens $\left[\leq\left[\Sigma_{9}\left[\right.\right.\right.$ knows the $\sigma_{\sigma_{3}}$ woman]]] - doesn't have the s-binder $\Sigma_{9}$ adjoined right next to a DP (in an A-position), but separated from it by $\leq$; such an adjunction is not warranted by our LF-construction rules (see (32c) below. This reflects the idea that only DPs can s-bind (allowing for s-binders to adjoin remote from the DP would also allow us to derive non-persistent propositions): ${ }^{6}$

I close this section with a classical donkey sentence within this analysis, in order to show that the modifications proposed here still allow us to derive the case that motivated Heim's original proposal: 
Every man who owns a donkey beats it.

a. LF: [every man who owns a donkey $\left[\Sigma_{3}\left[\leq\right.\right.$ [ beats the ( $_{3}$ donkey]]]]

b. $\left\{s \in S \mid\right.$ for every $x$ that is a man in $w_{s}$, any minimal situation $s^{\prime} \leq s$ in which there is a donkey $x$ owns is a situation which can be extended to a situation $s^{\prime \prime}$ in which $x$ beats the unique donkey in $\left.s^{\prime}\right\}$

\section{Embedded Quantifier Binding with Situations}

In this section I will provide the prerequisite definitions in detail and analyze representative constructions of each type.

\subsection{Definitions}

I start with the binder prefixes:
a. pronoun-binding (i-binding): $\llbracket \beta_{n} \mathrm{XP} \rrbracket^{g}=\lambda x . \llbracket \mathrm{XP} \rrbracket^{g\left[\text { pron }_{n} \rightarrow x\right]}(x)$ (A-positions only; XP can be any category of type $\langle\mathrm{e}, \mathrm{T}\rangle$ )
b. trace-binding: $\llbracket \mu_{n} \mathrm{XP} \rrbracket^{g}=\lambda x . \llbracket \mathrm{XP} \rrbracket^{g\left[t_{n} \rightarrow x\right]}$ (all positions, XP can be any category)
c. s(ituation)-binding: $\llbracket \Sigma_{n} \mathrm{XP} \rrbracket^{g}=\lambda x \cdot\left\{s \mid s \in \llbracket \mathrm{XP} \rrbracket^{g\left[\sigma_{n} \rightarrow s\right]}(x)\right\}$ (A-positions only; XP must be of type $\langle$ et $\rangle)^{7}$

Next I define situation extension, which we want to be able to apply to categories of any type that ends in $\langle\mathrm{t}\rangle:^{8}$

$$
\text { situation extension, flexible types version: } \llbracket \mathrm{Z} \leq \rrbracket^{g}=\mathrm{XT}\left(\llbracket \mathrm{Z} \rrbracket^{g}\right) \text {, where }
$$
a. $X T(p)=\left\{s_{1} \mid\right.$ there is a situation $s_{2}$ such that $s_{1} \leq s_{2}$ and $\left.s_{2} \in p\right\}$ if $p$ is in $D_{t}$, else
b. $X T(p)=\lambda \phi \cdot X T(p(\phi))$ if $p \in D_{\left\langle T_{1}, T_{2}\right\rangle}$ (with $\phi$ a variable of type $\left\langle T_{1}\right\rangle$ )

Since situations are parts of worlds, we need some way to make sure that determiners with a $\sigma_{n}$-index are always interpreted with respect to the counterpart of $g\left(\sigma_{n}\right)$ in the world of evaluation, rather than $g\left(\sigma_{n}\right)$ itself:
a. for all $s_{1}, \operatorname{cpc}\left(s_{1}\right)=$ the set of all counterparts to $s_{1}$
b. for all $s_{1}, s_{2}, c p\left(s_{1}\right)\left(s_{2}\right)=$ the $s \in \operatorname{cpc}\left(s_{1}\right)$ such that $s \leq w_{s_{2}}$
c. for all assignment functions $g$, variables $\sigma_{n}$, and situations $s_{1}, C P(g)\left(\sigma_{n}\right)\left(s_{1}\right)=$
i. $w_{s_{1}}$ if $n=0$
ii. $\quad c p\left(g\left(\sigma_{n}\right)\right)\left(s_{1}\right)$ otherwise

For the purpose of illustration I define the determiners the, 's, every and some; meanings for some other lexical items will be given as we go along: ${ }^{9}$ 


\section{determiner meanings:}

a. $\llbracket$ the $_{\sigma_{n}} \rrbracket^{g}=\lambda P_{1} . \lambda P_{2} .\left\{s \mid\right.$ there is an $x$ such that $\{x\}=\left\{x \mid C P(g)\left(\sigma_{n}\right)(s) \in P_{1}(x)\right\}$ and $\left.\min \left(P_{1}(x)\right) \cap P_{2}(x) \neq \varnothing\right\}=\mathrm{THE}^{g, \sigma_{n}}$

b. $\llbracket \mathrm{s}_{\sigma_{n}} \rrbracket^{g}=\lambda R . \lambda x . T H E^{g, \sigma_{n}}(R(x))=S^{g, \sigma_{n}}$

c. $\llbracket$ every $_{\sigma_{n}} \rrbracket^{g}=\lambda P_{1} \cdot \lambda P_{2} \cdot\left\{s \mid\right.$ for all $x$, if $C P(g)\left(\sigma_{n}\right)(s) \in P_{1}(x)$, then $\min \left(P_{1}(x)\right) \subseteq$ $\left.P_{2}(x)\right\}$

d. $\quad \llbracket$ some $_{\sigma_{n}} \rrbracket^{g}=\lambda P_{1} . \lambda P_{2} \cdot\left\{s \mid\right.$ there is an $x$ such that $C P(g)\left(\sigma_{n}\right)(s) \in P_{1}(x)$ and $\min \left(P_{1}(x)\right) \cap$ $\left.P_{2}(x) \neq \varnothing\right\}$

\subsection{Examples}

We are now ready to analyze the constructions under debate. Due to lack of space I will give a detailed calculation for one example only. For the later examples, annotated LFs will have to do.

\section{S-Binding by a DP with a Quantificational DP in its Specifier:}

Every boy's mother likes him.

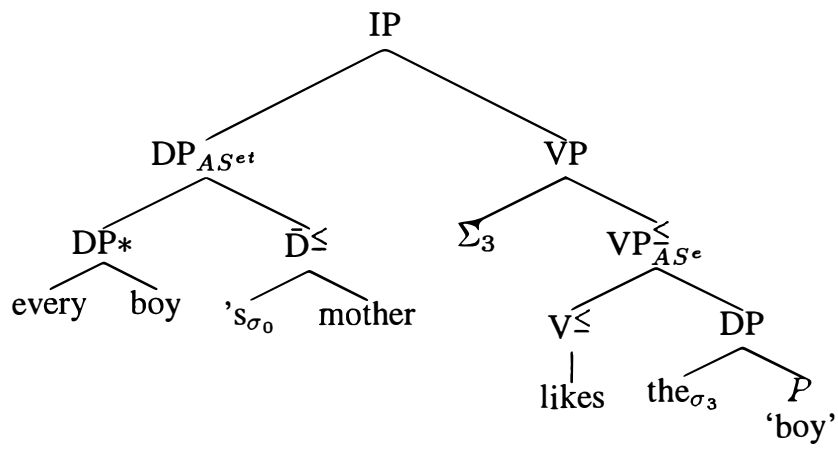

a. $\llbracket$ mother $\rrbracket^{g}=\lambda x_{1} \cdot \lambda x_{2} \cdot\left\{s \mid x_{2}\right.$ is $x_{1}$ 's mother in $\left.s\right\}=$ MOM

b. $\llbracket\left[{\text { 's } \sigma_{0}} \text { mother }\right]_{\bar{D}} \rrbracket^{g}={ }^{10} \lambda x_{1} \cdot \lambda P_{2} \cdot\left\{s \mid\right.$ there is an $x_{2}$ such that $\left\{x_{2}\right\}=\left\{x_{3} \mid C T(g)\left(\sigma_{0}\right)(s) \in \operatorname{MOM}\left(x_{1}\right)\left(x_{3}\right)\right\}$ and $\left.\min \left(M O M\left(x_{1}\right)\left(x_{2}\right)\right) \cap P_{2}\left(x_{2}\right) \neq \varnothing\right\}$

$=\lambda x_{1} \cdot \lambda P_{2} .\left\{s \mid\right.$ there is an $x_{2}$ such that $\left\{x_{2}\right\}=\left\{x_{3} \mid w_{s} \in \operatorname{MOM}\left(x_{1}\right)\left(x_{3}\right)\right\}$ and $\min \left(\operatorname{MOM}\left(x_{1}\right)\left(x_{2}\right)\right) \cap$ $\left.P_{2}\left(x_{2}\right) \neq \varnothing\right\}$

c. $\quad\left[\left[\text { 's }_{\sigma_{0}} \text { mother }\right]_{D \leq} \rrbracket^{g}=\lambda x_{1} . \lambda P_{2} \cdot\left\{s_{1} \mid\right.\right.$ there is an $s_{2}, s_{1} \leq s_{2}$ and an $x_{2}$ such that $\left\{x_{2}\right\}=\left\{x_{3} \mid w_{s_{2}} \in\right.$ $\left.M O M\left(x_{1}\right)\left(x_{3}\right)\right\}$ and $\left.\min \left(\operatorname{MOM}\left(x_{1}\right)\left(x_{2}\right)\right) \cap P_{2}\left(x_{2}\right) \neq \varnothing\right\}$

d. $\llbracket$ every $\sigma_{0}$ boy $\rrbracket^{g}=\lambda P_{2} .\left\{s \mid\right.$ for all $x$, if $C P(g)\left(\sigma_{n}\right)(s) \in B O Y(x)$, then $\left.\min (B O Y(x)) \subseteq P_{2}(x)\right\}$

e. $\llbracket\left[\text { every }_{\sigma_{0}} \text { boy's } \sigma_{\sigma_{0}} \text { mother }\right]_{D P_{A S e t}} \rrbracket^{g}$

$=\lambda P_{3} \cdot\left\{s_{3} \mid\right.$ for all $x$, if $C P(g)\left(\sigma_{r_{3}}\right)\left(s_{3}\right) \in B O Y(x)$, then $\min (B O Y(x)) \subseteq\left\{s_{1} \mid\right.$ there is an $s_{2}, s_{1} \leq s_{2}$ and an $x_{2}$ such that $\left\{x_{2}\right\}=\left\{x_{3} \mid w_{s_{2}} \in M O M\left(x_{1}\right)\left(x_{3}\right)\right\}$ and $\left.\left.\min \left(M O \bar{M}\left(x_{1}\right)\left(x_{2}\right)\right) \cap P_{3}\left(x_{2}\right) \neq \bar{\phi}\right\}\right\}$

f. $\quad \llbracket$ likes $\rrbracket^{g}=\lambda x_{1} \cdot \lambda x_{2} \cdot\left\{s \mid x_{2}\right.$ likes $x_{1}$ in $\left.s\right\}$

g. $\quad \llbracket[\text { likes }]_{V \leq} \rrbracket^{g}=\lambda x_{1} \cdot \lambda x_{2} \cdot\left\{s_{1} \mid\right.$ there is an $s_{2}, s_{1} \leq s_{2}$ and $x_{2}$ likes $x_{1}$ in $\left.s_{2}\right\}$

h. $\llbracket\left[\text { likes the } \sigma_{3} P\right]_{V P_{A S}} \rrbracket^{g}==\lambda x_{6} \cdot\left\{s_{1} \mid\right.$ there is an $x_{1}$ such that $\left\{x_{1}\right\}=\left\{x_{3} \mid C P(g)\left(\sigma_{3}\right)\left(s_{1}\right) \in\right.$ $\left.g(P)\left(x_{1}\right)\right\}$ and $\min \left(g(P)\left(x_{1}\right)\right) \cap\left\{s_{3} \mid\right.$ there is an $s_{2}, s_{3} \leq s_{2}$ and $x_{6}$ likes $x_{1}$ in $\left.\left.s_{3}\right\} \neq \varnothing\right\}$

i. $\left.\quad \llbracket\left[\text { likes the } \sigma_{3} P\right]_{V P P_{A S}}\right]^{g}=\lambda x_{6} \cdot\left\{s_{4} \mid\right.$ there is an $s_{1}, s_{4} \leq s_{1}$, and there is an $x_{1}$ such that $\left\{x_{1}\right\}=\left\{x_{3} \mid\right.$ $\left.C P(g)\left(\sigma_{3}\right)\left(s_{1}\right) \in g(P)\left(x_{1}\right)\right\}$ and $\min \left(g(P)\left(x_{1}\right)\right) \cap\left\{s_{3} \mid\right.$ there is an $s_{2}, s_{3} \leq s_{2}$ and $x_{6}$ likes $x_{1}$ in $\left.\left.s_{3}\right\} \neq \varnothing\right\}$

j. $\quad \llbracket \Sigma_{3}\left[\text { likes the } \sigma_{\sigma_{3}} P\right]_{V P_{A}^{\leq} \leq} \rrbracket^{g}=\lambda x_{6} \cdot\left\{s_{4} \mid\right.$ there is an $s_{1}, s_{4} \leq s_{1}$, and there is an $x_{1}$ such that $\left\{x_{1}\right\}=\left\{x_{3} \mid\right.$ $\left.c p\left(s_{4}\right)\left(s_{1}\right) \in g(P)\left(x_{1}\right)\right\}$ and $\min \left(g(P)\left(x_{1}\right)\right) \cap\left\{s_{3} \mid\right.$ there is an $s_{2}, s_{3} \leq s_{2}$ and $x_{6}$ likes $x_{1}$ in $\left.\left.s_{3}\right\} \neq \varnothing\right\}$ 
Note that now $C P(g)\left(\sigma_{3}\right)\left(s_{1}\right)$ (essentially a free variable) has been 'replaced' by $c p\left(s_{4}\right)\left(s_{1}\right)$, which means that $x_{1}$ is now the unique boy in (the $s_{1}$-counterpart to) $s_{4}$.

k. $\llbracket \mathrm{S} \rrbracket^{g}=\left\{s_{3} \mid\right.$ for all $x$, if $C P(g)\left(\sigma_{n}\right)\left(s_{3}\right) \in B O Y(x)$, then $\min (B O Y(x)) \subseteq\left\{s_{1} \mid\right.$ there is an $s_{2}, s_{1} \leq s_{2}$ and an $x_{2}$ such that $\left\{x_{2}\right\}=\left\{x_{3} \mid w_{s_{2}} \in \operatorname{MOM}\left(x_{1}\right)\left(x_{3}\right)\right\}$ and $\min \left(\operatorname{MOM}\left(x_{1}\right)\left(x_{2}\right)\right) \cap\left\{\bar{s}_{4} \mid\right.$ there is an $s_{1}, s_{4} \leq s_{1}$, and there is an $x_{1}$ such that $\left\{x_{1}\right\}=\left\{x_{3} \mid c p\left(s_{4}\right)\left(s_{1}\right) \in g(P)\left(x_{1}\right)\right\}$ and $\min \left(g(P)\left(x_{1}\right)\right) \cap\left\{s_{3} \mid\right.$ there is an $s_{2}, s_{3} \leq s_{2}$ and $x_{2}$ likes $x_{1}$ in $\left.\left.\left.\left.s_{3}\right\} \neq \varnothing\right\} \neq \varnothing\right\}\right\}$

$\approx\left\{s_{3} \mid\right.$ for all $x$, if $x$ is a boy in $w_{s_{3}}$ then every minimal situation $s_{5}$ of $x$ being a boy can be extended to a situation $s_{2}$, such that there is an $x_{2}$ which is the unique mother of $x$ in $w_{s_{2}}$ and at least one minimal situation $s_{4}$ of $x_{2}$ being $x$ 's mother can be extended to a situation $s_{1}$ such that there is an $x_{1}$, the unique $P$ in (the $s_{1}$-counterpart of) $s_{4}$, and at least one minimal situation of $x_{1}$ being a $\mathrm{P}$ can be extended to a situation $s_{6}$ in which $x_{2}$ likes $\left.x_{1}\right\}^{11}$

Aside: S- and I-Binding by a DP in SpecD: Note that every boy does neither s-bind nor i-bind in (36). Both of these are possible within the confines of its c-command domain, given that it sits in an A-position. While this makes no sense in the above example, it seems generally appropriate, as the following examples show:

a. every boy's pictures of himself

b. [[ every boy $\left.\left.\left.]_{D P}\left[\beta_{8}[\text { 's [ pictures [ of himself } 8]_{P P}\right]_{N P}\right]_{\bar{D}} \leq\right]_{\bar{D}}\right]_{D P_{A S} \text { et }}$

c. (Every boy had to take pictures of the girl he went to the prom with.) Every boy's pictures of the girl were collected for the yearbook.

d. [[ every boy $\left.\left.\left.]_{D P}\left[\Sigma_{8}[\text { 's [ [ pictures }]_{N \leq}\left[\text { of }\left[\text { the } \sigma_{8} \text { girl }\right]_{D P}\right]_{P P}\right]_{N P_{A S}}\right]_{\bar{D} \leq}\right]_{\bar{D}}\right]_{D P}$

Inverse linking: The analysis of the inverse linking cases doesn't bring anything new, except that the embedded QDP undergoes QR to get to its scope position:

Some person from every city likes it's beaches.

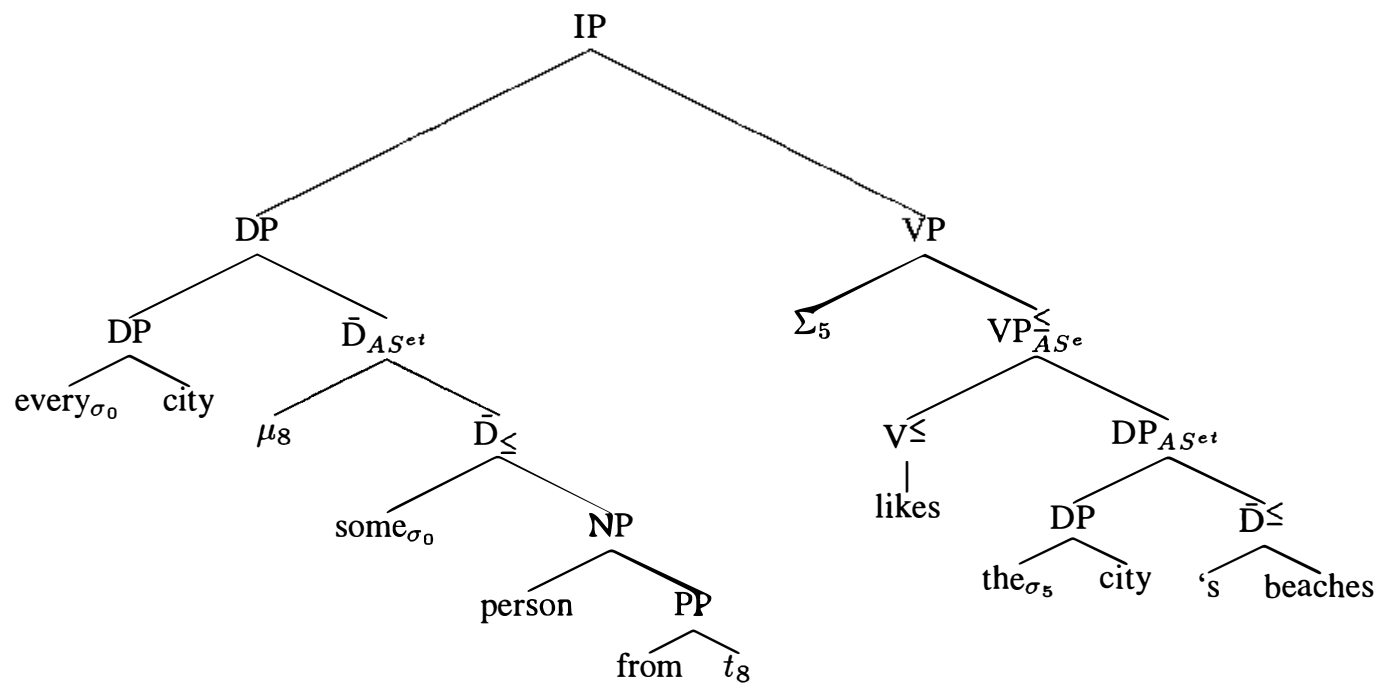

Here, every city binds its trace through $\beta_{8}$. It couldn't s-bind or i-bind anything, given that it is in an $\bar{A}$-position. Thus bindings like the following are correctly ruled out (contrast with (37)):
a. * its mayor's brother from every city (trying to mean every city's mayor's brother from that city)
b. * its enemies' destruction of every city (trying to mean every city's destruction by/through its enemies)


(Secondary) Weak Cross-Over: We observed in subsection 3.1 above that s-binding is possible only under a-command, which lead us to stipulate that $\Sigma$ can be adjoined next to an A-position only. The secondary weak cross-over effects follow from this, given that the apparent embedded quantifier binding is reanalyzed as s-binding by the CDP. For examples, the dependent reading indicated in (40) is ruled out because the container DP some person from every city lacks a position that a-commands its climate, making s-binding impossible. The closest we can get to binding it by some person from every city is the LF below, which fails to encode the intended reading: the $e_{\sigma_{11}}$ city refers to the unique city in $g\left(\sigma_{11}\right)$, i.e. it is not s-dependent on some person from every city, nor could it be, given that the latter occupies an $\overline{\mathrm{A}}$-position; the coindexing is thus semantically vacuous:

* Its climate is hated by some person in every city.

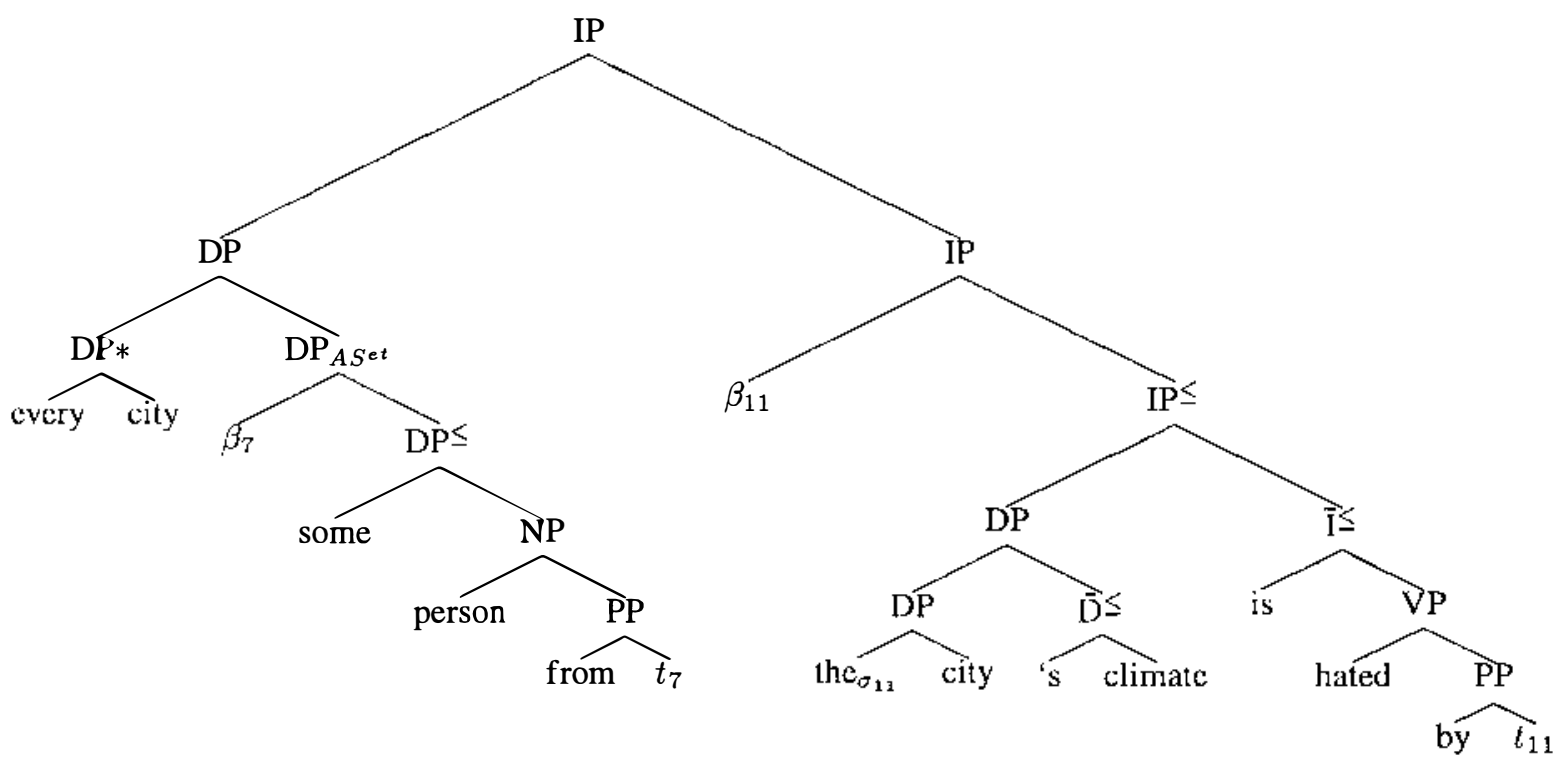

\subsection{Summary}

The machinery defined in this section preserves the advantages of the original Bach/Partee suggestion without running into its problems. We analyzed apparent binding without c-command as binding with c-command by the container DP. This binding, however, is s-binding, i.e. binding of a situation variable, rather than ordinary i-binding. By stipulating that s- and i-binding alike are restricted to A-positions, we extend our Reinhartian approach of the Cross-Over facts.

\section{S-Binding and I-Binding in VP-Ellipsis}

In this final section I want to add a few speculative remarks on the behavior of paycheck pronouns and dependent definites in general in VP-ellipsis constructions. The discussion draws heavily on Elbourne (2000b) and I freely include donkey sentences in the discussion, which I assume behave like EQB cases in all relevant respects.

\subsection{When Situation-Binding is Impossible}

According to the proposal explored in this paper, pronouns and definite descriptions behave alike in that they pick out a unique individual meeting a certain description in a particular situation. 'Donkey DPs' such as every woman who owns a donkey, DPs with a quantificational genitive such as every 
boy's mother, and inversely linked DPs such as some woman from every city all quantify over extended situations, i.e. situations that contain not just a woman but also a donkey (son, city, respectively). It was argued that pronouns and definites alike rely on such extended descriptions for an s-bound reading.

This much said, we can understand the contrast in:

a. Every farmer beats the donkey.

b. Every farmer who owns a donkey beats the donkey.

a. Every woman/mother likes the boy.

b. Every boy's mother likes the boy.

In the (a) sentences, the definite description can only get a contextual interpretation, i.e. refer to one and the same donkey/boy for each farmer/woman. This is predicted, given that every farmer and every woman quantify over minimal situations containing just a farmer/woman. S-Binding the donkey/the boy to the subject would yield an ill-formed reading since the definites would fail to refer; therefore the situation index on the must remain free.

In the (b) sentences on the other hand, a dependent interpretation is possible (i.e. different donkeys/boys per farmer/woman), given that the situations quantified over by the subject DP are extended situations, including a donkey/boy. Here, s-binding the definite by the subject is perfectly possible.

Given this, the VP-ellipsis facts are no longer mysterious:

a. ?? Every farmer who owns a donkey beats it, and every sailor does, too.

b. Every farmer who owns a donkey beats it, and every sailor who owns a donkey does, too.

a. ?? Every boy's cat recognized him, and every dog did, too.

b. Every boy's cat recognized him, and every boy's dog did, too.

The DPs every sailor and every dog in the (a)-examples quantify over minimal sailor/dog situations, which cannot be used to s-bind the hidden definite the donkey/boy in the elided VP. Hence the interpretation of that DP must be contextual, which leads to an odd meaning (note that the same oddity obtains if the antecedent contains a definite the donkey/boy). ${ }^{12}$ The DPs every sailor who owns a donkey and every boy's dog in the (b)-examples on the other hand, introduce extended situations which are capable of licensing a bound description via s-binding.

\subsection{Accommodation}

Let us now look at cases in which it appears that a pacheck pronoun or definite description is s-bound by a quantifier that, on the face of it, quantifies over minimal situations only:

Each villager got a donkey. Everyone from the Eastern part brought $\left\{\begin{array}{l}\text { it } \\ \text { the donkey }\end{array}\right\}$ into the stable.

Literally, we expect everyone from the Eastern part to quantify over minimal Easterner-situations, which, notably, are devoid of donkeys. It seems, however, that the context allows us to quantify over Easterner+donkey-situations, i.e. to treat the DP as if it were every Easterner who got a donkey. It appears that this is possible here, but not, say, in (41a), because the context entails the information that every villager (and hence every East-villager) has one donkey. I will refer to such cases like (45) as instances of accommodation, the idea being that additional descriptive material is accommodated into the restrictor of the quantifier. Accommodation can probably be invoked for cases of VP ellipsis in which EQB unexpectedly does license sloppy readings (see, once more, Elbourne (2000b) for parallel donkey sentences): 
a. Every boy's parents are supposed to buy him a dictionary, but many of them simply can't afford to/none of them can afford to.

b. Most people's publishers tell them when a book is going to appear, but Routledge doesn't.

c. Every boy's mother said she liked him. I didn't expect them to.

d. (child to father:) Everybody's dad supports them, but you don't!

In all these cases the DP that functions as an s-binder into the elided VP (many of them, Routledge, them and you, respectively) quantifies over or refers to individuals which are members of the set quantified over in the antecedent clause. For example, many of them quantifies over elements of the set of parents of boys, which means that the context entails that each element in that domain has a son; this in turn seems to allow for accommodation, i.e. for quantifying over parent+son-situations in the same way as in (45) above.

Examples like those in (46) are entirely unexpected under a binary individual quantification approach (i.e. an approach under which every boys parents quantifies over parent+boy pairs), simply because the ellipsis clause does not contain a complex DP of the prerequisite sort. Under the original paycheck approach they were allowed, but too easily, as pointed out in section 4.2. I believe that the s-binding approach gives us a way of making the necessary discriminations in terms of accommodation in a way that yields a reasonable approximation to the data.

\subsection{Pure Descriptions and Skolem Descriptions}

In the previous exposition we have used the pronouns-are-definite-descriptions approach throughout. According to Bach and Partee (1980)'s original proposal, however, pronouns go proxy for definite descriptions that contain a bound individual variable. That is, the him in every boy's mother loves him would not be interpreted as the boy but rather as her son. Let us call those two possibilities pure description and skolem description, respectively.

We saw earlier that both approaches run into the uniqueness-problem alike. This problem was shown to be remedied by the use of situation variables under the pure description approach. It should be obvious that the same effect occurs with skolem descriptions. To give but one illustration, if we assume that the LF for every boy's mother likes him involves the DP the $R x$, where $R$ will be instantiated as the son-of function and $x$ is a variable bound by every mother, the prerequisite LF will look like (47)(I leave out $\mathrm{AS}^{T}$ and $\leq$ superscripts in the following):

$$
\text { every boy's mother }\left[\Sigma_{3}\left[\beta_{4}\left[\text { likes }\left[\mathrm{THE}_{\sigma_{3}} R / \text { 'son of" } x_{4}\right]_{D P}\right]\right]\right]_{V P}
$$

In contradistinction to the pure description approach, (47) associates with every minimal mother +boy situation the unique son of that mother in that situation (rather than the unique boy in that situation). This doesn't yield any interpretive difference in this example, however, given that each such situation contains a son and no other boys anyway.

Are the two options -- interpreting the pronoun as a pure description or as a skolem description — just two ways of deriving the same meaning, then? And are they both available always? Presumably the answer is 'no' on both counts. Notice that a definite with a pronoun in it does not seem to rely on extended situations for interpretation: Every boy pets his cat is fine out of the blue, provided we can accommodate that every boy quantifies over single-cat owners only. As one might expect, such a DP can license both VP ellipsis and paycheck pronouns:

$$
\text { Every cat recognized its owner, and every } \operatorname{dog}\left\{\begin{array}{l}
\text { did } \\
\text { recognized him }
\end{array}\right\} \text {, too. }
$$

We know from the discussion of examples like (44) above that a DP like every dog cannot sbind a pure description in a context like this. What is going on in (48) then, must be i-binding. That is, its LF looks like (49): 


$$
\text { every dog }\left[\beta_{4}\left[\operatorname{recognized~}\left[\mathrm{THE}_{\sigma_{0}} R / \text { 'owner of' } x_{4}\right]_{D P}\right]\right]_{V P}
$$

Note that THE here is indexed $\sigma_{0}$, i.e. it designates $g\left(x_{4}\right)$ 's unique owner in the world. Obviously, this requires accommodation in the context given: It must be accommodated that every dog has an owner. This is different, however, from the situation in (44) above, where we would need to accommodate that every dog quantifies over dog+boy situations. It is not entirely clear why this accommodation should be harder than that above, but they are clearly different: The former states that the dogs have owners, whereas the latter says that when we talk about dogs, we really talk about dog+owner pairs.

Assuming that Elbourne's idea that paycheck pronouns can only be licensed by syntactic identity, it follows that for a pronoun to be interpreted as a skolem description, a 'skolem antecedent DP' needs to be present, as in (48) (and 'classical' paycheck sentences in general). In the absence of such an antecedent, only the pure description construal is possible, as is the case in all of our EQB examples and donkey sentences.

If furthermore, as I just argued, dependent readings with pure description depend on s-binding, whereas dependent readings with skolem descriptions can alternatively utilize i-binding, it follows that the former depend on extended situations, where the latter do not. So the fact that the former do not allow sloppy identity, while the latter do, finds a formal correlate.

\section{Conclusion}

I have shown how the paycheck pronoun approach can be modified into a binary quantification approach which avoids the problems associated with the simpler version and can still derive the Cross-Over facts. The machinery involved is complex. Is it independently motivated? I believe the answer is 'yes', if its is generally indicated to interpret definites as situation-dependent. The alternative would try to capture all s-binding effects through more sophisticated variants of i-binding, presumably of the unselective sort, but it is not clear at the present moment whether such a system would involve less complexity. In the meantime the approach developed here yields reasonable truth conditions, a uniform approach to all binding out of DP phenomena, and an elegant treatment of Cross-Over.

\section{Endnotes}

1. Throughout this paper I will use $x$ for individual variables (type $\langle\mathrm{e}\rangle$ ), $P$ for property variable (type $\langle$ et $\rangle), R$ for relations ( $\langle\mathrm{e},\langle$ et $\rangle\rangle), p$ for propositions $(\langle\mathrm{t}\rangle), G$ for generalized quantifiers ( $\langle$ et, $\mathrm{t}\rangle$ ), $s$ for situations, $T$ as a variable over types, and greek letters for variables of flexible type. Where necessary, variables will be subscripted to distinguish them.

2. Essentially the same phenomenon is found in multiple wh-questions like Which picture of which governor pleased his wife? (from Safir (1984):626). Since I cannot discuss question semantics in this paper I will ignore them henceforth, but I think any approach in which the $w h$-phrase binds an individual variable can be combined with the approach developed here.

3. This version of the rule is not fully generalized in that it allows one to skip one argument only (though one of an arbitrary type), but this is all we need in this paper. I use the subscript notation $X P_{A S^{T}}$ for notational convenience, though a proper version should simply adjoin a type-lifting operator to the $\mathrm{Z}$-argument in the rule, i.e. [DP Z $]_{A S^{T}}$ would be replaced by [DP [ $\left.A S^{T} Z\right]$ ], with the semantics for $A S^{T}$ being $\lambda \xi . \lambda G . \lambda \psi \cdot G(\lambda x . \xi(x)(\psi))$.

4. It is of course conceivable that each of those definite DPs contains a hidden individual variable (i.e. the title is its title or the title of it at LF), but the line I need to explore is obviously that they don't. Rather, I want them to refer to the unique driver/movie/... in a particular situation, and that situation is introduced by the subject DPs in the above examples. 
5. The technical use of the term situation might be confusing at first, since it is intuitively unclear what a minimal situation containing a movie (or a boy and his mother for that matter) would look like. As I lack the space to go into the foundations of situation semantics here, I have to refer the reader to Kratzer (1989) and the references therein.

6. An alternative that comes to mind is to define $\llbracket \leq \mathrm{A} \rrbracket^{g}=\left\{s \mid w_{s} \in \llbracket \mathrm{A} \rrbracket^{g}\right\}$. Under this interpretation, even if DPs could be evaluated relative to the situation introduced by $\leq$, this interpretation would always amount to the same as if they had been indexed $\sigma_{0}$. Currently I cannot see any reason to choose one option over the other.

7. A flexibe types version of this rule is needed for, e.g. example (37d). Its definition is as follows: $\llbracket \Sigma_{n} \mathrm{XP} \rrbracket^{g}=\lambda G . S B\left(\lambda s . \llbracket \mathrm{XP} \rrbracket^{g\left[\sigma_{n} \rightarrow s\right]}\right)(\mathrm{G})$, where $\left.S B(\psi)(G)=\mathrm{i}\right) G(\lambda x .\{s \mid s \in \psi(s)(x)\})$ if $\psi \in D_{e t}^{S}$, otherwise ii) $\lambda \phi . S(\lambda s . \lambda x . \psi(s)(x)(\phi))(G)$ if $\psi \in D_{T_{1}, T_{2}}$, with $\phi \in D_{T_{1}}$.

8. As with the $A S^{T}$ operation before, I abbreviate $[\leq Z]$ as $Z \leq$ for the sake of brevity.

9. $\quad$ Note that since $x$ is a part of $w_{s}$ in all these definitions, so are $P_{1}(x)$ and $P_{2}(x)$, i.e. these meanings lead to contingent propositions. They do, however, yield very different lumping properties from those in Kratzer (1989)), a problem I ignore here.

10. This node doesn't exist in the tree, of course, but I give its meaning as an intermediary step.

11. This implementation of the analysis hinges on the assumption that if $x$ is a boy, and $s_{4}$ is a minimal situation of $x_{2}$ being $x$ 's mother, then $s_{4}$ is a situation that contains a boy. Sure enough $s_{4}$ contains $x$, but does it 'contain' $x$ 's boyhood? If the answer to this question negative, the analysis presented in the main text cannot be maintained as is. One amendment I can think of is appeal to accommodation. Another one is to leave the restrictor of the wide-scope DP within the narrow scope DP (i.e. by copying). I leave these issues for further research.

12. Purely contextual reading for these indefinites seems very hard to get, presumably due to some parallelism requirement on VP ellipsis: If the antecedent VP contains an s-bound pronoun, the elided VP must, too. As Elbourne (2000b) notes, sentences like (43a) tend to get across-the-board readings, in which the sailors beat the farmers' donkeys. I will not speculate about how to get these.

\section{References}

Bach, Emmon, and Barbara H. Partee. 1980. Anaphora and Semantic Structure. Papers from the Parasession on Pronouns and Anaphora, edited by J. Kreiman and A. Ojeda, CLS, 1-28.

Barker, Chris. 2001a. Continuations and the nature of quantification. Unpubl.ms.UC San Diego.

—. 2001b. Integrity: a syntactic constraint on quantifier scoping. Unpubl.ms.UC San Diego.

Berman, Stephen R. 1987. Situation-based Semantics for Adverbs of Quantification. University of Massaxgusetts Occasional Papers, edited by Anne Vainikka, vol. 12. UMass, Amherst.

Büring, Daniel. 2001. Binding out of DP and Weak Cross-Over. Manuscript, UCLA.

Cooper, Robin. 1979. The Interpretation of Pronouns. Syntax and Semantics, vol. 10, 61-92.

Dimitriadis, Alexis. 1999. Reconciling Dependent Plurals with each other. Proceedings of SALT IX, 52-69. Ithaca, NY: CLC Publications.

Elbourne, Paul. 2000a. E-Type Pronouns as Definite Articles. WCCFL 2000 Proceedings, 83-96.

—. 2000b. E-Type Pronouns as NP-Ellipsis. MIT.

- 2001. On the Semantics of Pronouns and Definite Articles. WCCFL 2001 Proceedings, 101-114. 
Evans, Gareth. 1977. Pronouns, Quantifiers, and Relative Clauses. The Canadian Journal of Philosophy 7:467-536.

—. 1980. Pronouns. Linguistic Inquiry 11:337-362.

Fintel, Kai von. 1994. Restrictions on Quantifier Domains. Ph.D. thesis, UMass, Amherst.

Heim, Irene. 1990. E-Type Pronouns and Donkey Anaphora. Linguistics \& Philosophy 13:137-177.

Heim, Irene, and Angelika Kratzer. 1998. Semantics in Generative Grammar. Oxford: Blackwell Publishers.

Higginbotham, James. 1980. Pronouns and Bound Variables. Linguistic Inquiry 11:679-708.

Hornstein, Norbert. 1995. Logical Form — From GB to Minimalism. Blackwell.

Huang, C.-T. James. 1982. Logical Relations in Chinese and the Theory of Grammar. Ph.D. thesis, MIT.

Jacobson, Pauline. 1977. The Syntax of Crossing Coreference Sentences. Ph.D. thesis, UC Berkeley. (published 1980 by Garland Press).

—. 1999. Towards a Variable Free Semantics. Linguistics \& Philosophy 22:117-184.

- 2000. Paycheck Pronouns, Bach-Peters Sentences, and Variable Free Semantics. Natural Language Semantics 8:77-155.

Kadmon, Nirit. 1987. On Unique and Non-unique Reference and Asymmetric Quantification. Ph.D. thesis, UMass, Amherst.

Kratzer, Angelika. 1989. An Investigation of the Lumps of Thought. Linguistics \& Philosophy 12:607653.

Larson, Richard. 1987. Quantifying into NP. Unpubl.ms.

Lasnik, Howard. 1976. Remarks on Coreference. Linguistic Analysis 2:1-32. Reprinted in Lasnik (1989).

—. 1989. Essays on Anaphora. Kluwer.

May, Robert. 1977. The Grammar of Quantification. Ph.D. thesis, MIT.

—. 1985. Logical Form. Cambridge, Mass.: MIT Press.

—. 1988. Bound Variable Anaphora. Mental Representations, 85-104. Cambridge University Press.

Neale, Stephen. 1990. Descriptions. Cambridge, MA: MIT Press.

Reinhart, Tanya. 1983. Anaphora and Semantic Interpretation. University of Chicago Press.

Ruys, E.G. 2000. Weak Crossover as a Scope Phenomenon. Linguistic Inquiry 31:513-539.

Safir, Ken. 1984. Multiple Variable Binding. Linguistic Inquiry 15:603-638.

Sag, Ivan A. 1976. Deletion and Logical Form. Ph.D. thesis, MIT.

Tomioka, Satoshi. 1999. A Sloppy Identity Puzzle. Natural Language Semantics 7:217-241. 